\title{
A Study on Sleeping Pattern among Undergraduate Medical Students of a Tertiary Care Teaching Hospital of Kolkata
}

\author{
Mausumi Basu', Sanjay Kumar Saha', Somak Majumder ${ }^{1, *}$, Sita Chatterjee ${ }^{2}$, Raghunah Misra ${ }^{1}$
}

Mausumi Basu', Sanjay Kumar Saha', Somak Majumder ${ }^{1, *}$, Sita Chatterjee ${ }^{2}$, Raghunah Misra' ${ }^{1}$

'Department of Community Medicine, IPGME \& $R$ and SSKM Hospital, Kolkata, West Bengal, INDIA.

2Department of Community Medicine, KPC Medical College and Hospital, West Bengal, INDIA.

\section{Correspondence}

\section{Dr. Somak Majumder}

Demonstrator, Department of Community Medicine, IPGME \& R and SSKM Hospital, Kolkata-700020, West Bengal, INDIA.

Mobile no: +91 8697369790

Email: somakm88@gmail.com

\section{History}

- Submission Date: 29-05-2019;

- Revised Date: 04-10-2019;

- Accepted Date: 12-11-2019;

DOI : 10.5530/ijmedph.2019.4.26

Article Available online

http://www.ijmedph.org/v9/i4

\section{Copyright}

(C) 2019 Phcog.Net. This is an openaccess article distributed under the terms of the Creative Commons Attribution 4.0 International license.

\begin{abstract}
Introduction: Medical students are a subgroup of the general population who are more vulnerable to poor sleep quality. Objectives: To assess the sleeping pattern and determinants among the medical undergraduate students of a Government teaching Hospital, Kolkata. Materials and Methods: An Institution-based cross-sectional study was conducted among 293 undergraduate medical students of a teaching Hospital of Kolkata from October 2017 to December 2017 using a pre-designed, pre-tested structured questionnaire, Pittsburgh Quality of Sleep Index (PSQI) score and Epworth Daytime Sleepiness Scale (EDSS). Results: About 24.91\% of students had daytime sleepiness as per Epworth Daytime Sleepiness Scale (EDSS) and about $63.48 \%$ had poor sleep quality as per Pittsburgh Quality of Sleep Index (POSI) score. There was significant correlation between Poor Sleep Quality (PSQI) score and age, year of study, hostel residence, socio-economic condition, body mass index, smoking, alcohol intake, caffeine consumption, exercise, stress and excessive use of mobile/laptop. EDS score was significantly associated with age, semester of study, residence and habit of exercise. Conclusion: To improve the sleep quality of medical students, we should provide a positive environment by establishing counselling facilities and promoting good sleep hygiene.

Key words: Medical students, Sleep, PSQI, EDSS, Tertiary hospital.
\end{abstract}

\section{INTRODUCTION}

Every individual of the environment requires a period of rest to enhance and empower its work ability. As per the expert panel report published in Sleep Health-The Journal of the National Sleep Foundation 2015, in younger adults (18-25): Sleep range is 7-9 hr. Poor sleep quality is believed one of the most obvious public health problems and the rates of poor sleep quality are increasing in both developing and modern societies. ${ }^{1}$ Sleep deprivation may have serious health consequences; it may be associated with decrease in the immunity, unhealthy behaviour and may lead to psychological problems and metabolic problems like diabetes mellitus, hypertension, metabolic syndrome and obesity. ${ }^{2}$ Adequate quality of sleep is a prerequisite for optimum functioning of a student's mind and body. Concentration and attention difficulties along with poor academic performance are linked with poor sleep quality among students ${ }^{3}$ because good sleep is needed for the best of neuro-cognitive functions, psychomotor performance, physical and mental health. ${ }^{1}$ Sleep problems are common in the general population and approximately one-third of adults report some form of insomnia. Medical students are a subgroup of the general population who are more vulnerable to poor sleep quality. ${ }^{1}$ Medical students are assumed to be a stressful group of students $^{4,5}$ due to their long study years, high academic load, frequent examination, fear of failure, hectic clinical duties, emotionally challenging work and the highly demanding lifestyle. ${ }^{1}$ Several studies have reported the prevalence of sleep problems among medical students of different nationalities. Global epidemiological data about sleep problems among medical students reported a very wide range of $19 \%$ to $90 \%{ }^{1}$ Poor sleep quality leads to Excessive Daytime Sleepiness (EDS) which affect the performance of medical students. Thus, identification of poor sleep quality among medical students is an essential step to know the load of the problem and managing it effectively which can ultimately lead to improve quality of patients' care provided by budding physicians. ${ }^{1}$ As sleep deprivation and associated symptoms have become a widespread problem among the undergraduate medical students and as this problem has not been properly judged since long in this part of India, a study was conducted to explore the sleeping pattern and determinants among the medical undergraduate students of a teaching Hospital, Kolkata.

\section{MATERIALS AND METHODS}

\section{Type of study}

Study design, study setting, study period and study population: An Institution-based observational, descriptive, study, cross-sectional in design, was conducted among undergraduate medical students of a
Cite this article : Basu M, Saha SK, Majumder S, Chatterjee S, Misra R. A Study on Sleeping Pattern among Undergraduate Medical Students of a Tertiary Care Teaching Hospital of Kolkata. Int J Med Public Health. 2019;9(4):118-24. 
teaching Hospital of Kolkata from October 2017 to December 2017, a duration of 3 months.

Inclusion criteria: Undergraduate medical students of all semesters who were present during the data collection period and gave informed written consent to participate in the study.

Exclusion criteria: Seriously ill, currently using sedative medications for any medical conditions.

Study tools were a predesigned pre-tested structured self- administered Questionnaire, Pittsburg Quality of Sleep Index (PQSI) ${ }^{6,7}$ scale and Epworth

Daytime Sleepiness Scale (EDSS). ${ }^{8}$ The questionnaire had four parts.

Part I

Consisted of information on the socio-demographic profile and lifestyle questions;

Part II consisted of questions of Pittsbur Quality of Sleep Index (PQSI) scale; ${ }^{6,7}$

Part III dealt with questions of Epworth Daytime Sleepiness Scale (EDSS) ${ }^{8}$ and

Part IV was measurement of Height and Weight to calculate Body Mass Index (BMI).

The questionnaire was designed in consultation with three experts; 2 from community medicine and 1 from respiratory medicine department, it was pretested on fifty (50) undergraduate medical students of the same institution; then modified (issues encountered were some lifestyle questions and those were modified during pre-testing), necessary changes were done and validated by another 3 experts. Pittsburg Quality of Sleep Index (PQSI) scale and Epworth Daytime Sleepiness Scale (EDSS) were already validated in Indian setting. Pittsburgh Sleep Quality Index (PSQI) validated in a sample of Indian university students in New Delhi, India in 2015 by Manzar MD et al. Validity of ESS in the Hindi language was done at a tertiary care hospital in North India by Kanabar et al.

Study variables: Socio-demographic profile (age, gender, semester, current residence, type of family, Per Capita Monthly Income), lifestyle questions (Tobacco, Alcohol, Excessive Caffeine intake, Exercise, Mobiles, laptops and internet use $>2 \mathrm{hr} /$ day), 10 questions of PQSI, 8 questions of EDSS.

Sample size and sampling technique: About 293 undergraduate MBBS students were selected using non-random convenience sampling technique. It was decided to collect information from all undergraduate students of this institution but is spite of repeated (three) visits, only 293 students were available during the data collection period. All gave consent for participation in the study. Thus, the response rate was cent percent.

\section{Data Collection Technique}

After getting the Institutional Ethics Committee clearance, the study population were briefed about the purpose and nature of the study; their informed consent was taken where confidentiality and anonymity were ensured in all aspects. Then, they were instructed to fill out the questionnaire completely and truthfully. Finally, their height and weight were measured following standard techniques and BMI were calculated. Collection of data were done for four (4) weeks under the supervision of authors and with the help of 12 medical students.

\section{Statistical Analysis}

Data were entered in Microsoft Office Excel 2010; analysis was done with Statistical Package for the Social Sciences (SPSS) Version 16.0 (Chicago, Illinois, USA). Descriptive results were expressed by frequency and percentages. For the association between various factors and sleeping pat- tern, Chi-square tests and 95\% Confidence Intervals (CI) were calculated. $P<0.05$ was considered statistically significant.

\section{Operational definition}

1. Current cigarette smoker: Defined as persons who reported smoking at least 100 cigarettes in their lifetime and who, at the time of survey, smoked either every day or some days (CDC).

2. Smokeless Tobacco: Pan parag, Khaini, Gutka, Zarda etc.

3. Alcohol consumption: One who drinks alcohol every day during the study period.

4. Excessive Caffeine intake: Drinks per day-227 millilitres ( $>6$ cups) serving of coffee, espresso, tea, soft drinks, hot chocolate, energy drink or 42.5 grams of chocolate.

5. Pittsburgh Sleep Quality Index (PSQI): ${ }^{6,7}$ It is a self- report questionnaire to assess the quality of sleep. There are Nineteen items with seven "component" scores, each of which has a range from ' 0 ' to ' 3 ', ' 0 ' indicates no difficulty and ' 3 ' indicates severe difficulty. The sum of these seven component scores yields one PSQI global score with a range of ' 0 ' to ' 21 ' points, ' 0 ' indicates no difficulty and ' 21 ' indicates severe difficulty in all areas.

The 7 component scores are: 1 . sleep quality, 2. sleep latency, 3. sleep duration, 4 . sleep efficiency, 5 . sleep disturbances, 6 . use of sleeping medication and 7. daytime dysfunction.

Good sleep quality is defined as PQSI score $\leq 5$, while scores above 5 demonstrate poor quality.

6. Epworth Sleepiness Scale (EDSS): ${ }^{8}$ It is a scale to measure daytime sleepiness using a very short questionnaire, introduced in 1991 by Dr. Murray Johns of Epworth Hospital in Melbourne, Australia. There are 8 questions and scores are range from ' 0 ' to ' 3 ' for each question.

$0=$ would never doze $1=$ slight chance of dozing $2=$ moderate change of dozing 3 = high chance of dozing

The higher the ESS score, the higher that person's average sleep propensity in daily life (ASP). The eight questions added together to get a single number which range from ' 0 ' to ' 24 '. A number in the $0-10$ range is considered to be normal while a number in the 11-12 is of borderline and 13-24 range indicates expert medical advice to be sought.

In general, ESS scores can be interpreted as follows 0-5 Lower Normal Daytime Sleepiness

6-10 Higher Normal Daytime Sleepiness

11-12 Mild Excessive Daytime Sleepiness

13-15 Moderate Excessive Daytime Sleepiness

16-24 Severe Excessive Daytime Sleepiness

The activities included in the questionnaire are:

- $\quad$ sitting and reading

- watching TV

- $\quad$ sitting inactive in a public place, such as a meeting or theatre

- $\quad$ riding as a passenger in a car for an hour without a break

- lying down to rest in the afternoon when circumstances permit

- $\quad$ sitting and talking to someone

- $\quad$ sitting quietly after a lunch without alcohol

- $\quad$ sitting in a car, stopped for a few minutes in traffic

\section{RESULTS}

Table 1 described distribution of the study population according to their socio-demographic profile. Their age ranged from 17 to 25 years, $22.18 \%$ students were of 19 years, $62.12 \%$ were males, about $40.16 \%$ of students were from first semester, about $61.77 \%$ were hostel resident, $81.23 \%$ of 
Table 1 : Distribution of the study population according to socio-demographic profile $(\mathrm{N}=293)$

Socio Demographic Profile Number Percentage (n) (\%)

\section{Age (years)}

17

18

19

20

21

22

23

24

25

\section{Gender}

Male

Female

Semester

First

Third

Fifth

Seventh

Ninth

Current residence

Day scholar

Hostel resident

Type of family

Nuclear

Joint

Per Capita Monthly Income According to

Modified BG Prasad's Scale, 2017

Upper $(>=6254)$

Upper Middle (3127-6253)

Middle (1876-3126)

Lower Middle (938-1875)

Lower $(<938)$

Body Mass Index (BMI) $\left(\mathrm{kg} / \mathrm{m}^{2}\right)$ (WHO)

$<18.5$ (Underweight)

18.5-24.9 (Normal weight)

25-29.9 (Pre obese/overweight)

30-34.9 (Obese classI)

BMI (Asia-Pacific)

$<18.5 \quad$ (Underweight)

18.5-22.9 (Normal weight)

23-24.9 (Overweight)

$>=25 \quad$ (Obese)
Table 2: Distribution of the study population according to lifestyle $(\mathrm{N}=293)$

\begin{tabular}{|c|c|c|}
\hline Lifestyle & Number(n) & Percentage (\%) \\
\hline \multicolumn{3}{|c|}{ Addiction } \\
\hline \multicolumn{3}{|c|}{ Tobacco } \\
\hline Yes & 39 & 13.31 \\
\hline No & 254 & 86.69 \\
\hline \multicolumn{3}{|c|}{ Alcohol } \\
\hline Yes & 37 & 12.63 \\
\hline No & 256 & 87.37 \\
\hline \multicolumn{3}{|c|}{ Caffeine } \\
\hline Yes & 216 & 73.72 \\
\hline No & 77 & 26.28 \\
\hline \multicolumn{3}{|c|}{ Habit of exercise } \\
\hline Yes & 160 & 54.61 \\
\hline No & 133 & 45.39 \\
\hline \multicolumn{3}{|c|}{ Mobiles, laptops and internet use $>2 \mathrm{hr} /$ day } \\
\hline Yes & 288 & 98.29 \\
\hline No & 05 & 01.71 \\
\hline \multicolumn{3}{|c|}{ Stress* } \\
\hline Yes & 172 & 58.70 \\
\hline No & 121 & 41.30 \\
\hline Total & 293 & 100.00 \\
\hline
\end{tabular}

* If any identifiable external stressors during last one year(like any death in family, breaking relationship, examination failure, trouble concentrating etc.)

the study population were from nuclear family, $78.15 \%$ of students belonged to upper class as per modified B. G. Prasad Scale 2017 and 70.65\% had normal BMI as per WHO classification.

It was seen from Table 2 that, out of 293 medical students, smoking was reported by $39 / 293$ (13.32\%) students, regular alcohol intake was done by 37/293(12.63\%) students, excessive caffeine intake was revealed by $216 / 293(73.73 \%)$ students, regular exercise was done by $160 / 293$ (54.61\%) students, stress was reported by $172 / 293$ (59.04\%) medical students and excessive use of social media at night by $288 / 293$ (98.29\%) undergraduate medical students.

It was found that $24.91 \%$ of students had daytime sleepiness as per EDSS and about $63.48 \%$ had poor sleep quality as per PQSI score [Table 3].

It was seen from Table 4 that, there was significant association between Poor Sleep Quality (PSQI) score and age, year of study, hostel residence, socio economic status, body mass index, smoking, alcohol intake, caffeine consumption, exercise, stress and excessive use of mobile/laptop ( $p$ value $<0.05)$.

EDS score was significantly associated with age, semester of study, residence and habit of exercise [Table 5].

\section{DISCUSSION}

Medical students have various life constraints which cause their irregular sleep habits, evidenced by various studies around the world.

The PSQI tool used in this study is a widely used inventory for assessing sleep quality and has sufficient intrinsic reliability and validity across both medical and non-medical population groups. It is a reliable measure of sleep quality in the Indian context too. 
Table 3: Distribution of the study population according to their Sleeping pattern $(N=293)$

Sleeping pattern

Number(n)

Percentage (\%)

EPIWORTH DAYTIME SLEEPINESS SCALE (EDSS)

$\begin{array}{crc}\text { Lower normal (0-5) } & 115 & 39.25 \\ \text { Higher normal (6-9) } & 105 & 35.84 \\ \text { Mild excess (11-12) } & 73 & \mathbf{2 4 . 9 1}\end{array}$

PITTSBURGH SLEEP QUALITY INDEX SCORE (PSQI)

Good sleep quality $(<=5)$

107

36.52

Poor sleep quality $(>5)$

186

63.48
In the present study $63.48 \%$ undergraduate medical students tested positive for poor sleep quality as per PSQI scale. Using the same PSQI instrument, many previous and recent studied across the globe revealed a high percentage of undergraduate medical students suffer from poor sleep.

Some recent study results coincide with the present study findings. ${ }^{9-13}$ About $67.42 \%$ students reported poor sleep quality in a study by Priya et al. at Pawapuri, ${ }^{9} 70.4 \%$ by Ibrahim et al. at Saudi Arabia, ${ }^{10} 63.5 \%$ by Gassara et al. at Tunisia, Africa, ${ }^{11} 62.6 \%$ by Shad et al. at Delhi, ${ }^{12} 79.3 \%$ by Machado-Duque at Universidad Tecnológica de Pereira (Columbia). ${ }^{13}$ Such high rates of poor sleep among medical students from different countries of globe are of great concern. This can be improved through counselling and healthy lifestyle.

\begin{tabular}{|c|c|c|c|c|c|c|}
\hline \multirow[t]{2}{*}{ Co variable } & \multirow[t]{2}{*}{ Group } & \multicolumn{3}{|c|}{ PSQI score } & \multirow[t]{2}{*}{$\chi^{2}$ Value } & \multirow[t]{2}{*}{$P$ value } \\
\hline & & Good $n(\%)$ & Poor n(\%) & Total n(\%) & & \\
\hline \multirow[t]{2}{*}{ Age in years } & $<=20$ & $16(13.56)$ & $102(86.44)$ & $118(40.27)$ & 44.92 & $<0.001$ \\
\hline & $>20$ & $91(52.00)$ & $84(48.00)$ & $175(59.73)$ & & \\
\hline \multirow[t]{2}{*}{ Gender } & Male & $69(37.91)$ & $113(62.09)$ & $182(62.12)$ & 00.40 & 0.52 \\
\hline & Female & $38(34.23)$ & $73(65.77)$ & $111(37.88)$ & & \\
\hline \multirow[t]{5}{*}{ Semester } & First & $36(30.25)$ & $83(69.75)$ & $119(40.61)$ & 11.20 & 0.02 \\
\hline & Third & $28(35.44)$ & $51(64.56)$ & $79(26.96)$ & & \\
\hline & Fifth & $16(33.33)$ & $32(66.67)$ & $48(16.38)$ & & \\
\hline & Seventh & $14(58.33)$ & $10(41.67)$ & $24(08.19)$ & & \\
\hline & Ninth & $13(56.52)$ & $10(43.48)$ & $23(07.85)$ & & \\
\hline \multirow[t]{2}{*}{ Residence } & Day scholar & $55(49.11)$ & $57(50.89)$ & $112(38.2)$ & 12.40 & $<0.001$ \\
\hline & Hostel resident & $52(28.73)$ & $129(71.27)$ & $181(61.8)$ & & \\
\hline \multirow[t]{2}{*}{ Type of family } & Joint & $22(40.00)$ & $33(60.00)$ & $55(18.77)$ & 00.35 & 0.55 \\
\hline & Nuclear & $85(35.71)$ & $153(64.29)$ & $238(81.23)$ & & \\
\hline \multirow[t]{5}{*}{ PCMI(Rs/month) } & $<938$ & $01(50.00)$ & $01(50.00)$ & $02(00.68)$ & 12.55 & 0.04 \\
\hline & $939-1875$ & $06(46.15)$ & $07(53.85)$ & $13(04.44)$ & & \\
\hline & $1876-3126$ & $05(45.45)$ & $06(54.55)$ & $11(03.75)$ & & \\
\hline & $3127-6253$ & $14(37.84)$ & $23(62.16)$ & $37(12.63)$ & & \\
\hline & $>6254$ & $81(35.22)$ & $149(64.78)$ & $230(78.50)$ & & \\
\hline \multirow[t]{4}{*}{ BMI (in kg/m²) } & $<18.5$ & 06(19.35) & $25(80.65)$ & $31(10.58)$ & 11.90 & $<0.001$ \\
\hline & $18.5-24.9$ & $73(34.60)$ & $138(65.40)$ & $211(72.01)$ & & \\
\hline & $25-29.9$ & $26(54.17)$ & $22(45.83)$ & $48(16.38)$ & & \\
\hline & $30-34.9$ & $02(66.67)$ & $01(33.33)$ & 03(01.03) & & \\
\hline \multirow[t]{2}{*}{ Habit of exercise } & Yes & $73(45.63)$ & $87(54.37)$ & $160(54.61)$ & 12.60 & $<0.001$ \\
\hline & No & $34(25.56)$ & $99(74.44)$ & $133(45.39)$ & & \\
\hline \multirow[t]{2}{*}{ Tobacco intake } & Yes & $08(20.51)$ & $31(79.49)$ & $39(13.31)$ & 04.97 & 0.02 \\
\hline & No & $99(38.98)$ & $155(61.02)$ & $254(86.69)$ & & \\
\hline \multirow[t]{2}{*}{ Alcohol intake } & Yes & $08(21.62)$ & $29(78.38)$ & $37(12.63)$ & 04.05 & 0.04 \\
\hline & No & $99(38.67)$ & $157(61.33)$ & $256(87.37)$ & & \\
\hline \multirow[t]{2}{*}{ Excessive Caffeine intake } & Yes & $69(31.94)$ & $147(68.06)$ & $216(73.72)$ & 07.42 & $<0.001$ \\
\hline & No & $38(49.35)$ & $39(50.65)$ & $77(26.28)$ & & \\
\hline \multirow[t]{2}{*}{ Stress } & Yes & $33(19.19)$ & $139(80.81)$ & $172(58.70)$ & 54.00 & $<0.001$ \\
\hline & No & $74(61.16)$ & $47(38.84)$ & $121(41.30)$ & & \\
\hline \multirow[t]{2}{*}{ Mobile, laptop, internet $>2 \mathrm{~h} / \mathrm{d}$} & Yes & $103(35.76)$ & $185(64.24)$ & $288(98.29)$ & 04.15 & 0.04 \\
\hline & No & $04(80.00)$ & $01(20.00)$ & $05(01.71)$ & & \\
\hline Total & & $107(36.52)$ & $186(63.48)$ & 293(100.00) & & \\
\hline
\end{tabular}




\begin{tabular}{|c|c|c|c|c|c|c|c|}
\hline \multirow[t]{3}{*}{ Co variable } & \multirow[t]{3}{*}{ Group } & \multicolumn{4}{|c|}{ EDSS score } & \multirow[t]{3}{*}{$\chi^{2}$ Value } & \multirow[t]{3}{*}{$P$ value } \\
\hline & & $0-5$ & $6-10$ & $11-12$ & Total & & \\
\hline & & $n(\%)$ & $n(\%)$ & $n(\%)$ & $n(\%)$ & & \\
\hline \multirow[t]{2}{*}{ Age in years } & $<=20$ & $34(28.82)$ & $42(35.59)$ & $42(35.59)$ & $118(40.27)$ & 14.50 & $<0.001$ \\
\hline & $>20$ & $81(46.29)$ & $63(36.00)$ & $31(17.71)$ & $175(59.73)$ & & \\
\hline \multirow[t]{2}{*}{ Gender } & Male & $75(41.21)$ & $66(36.26)$ & $41(22.53)$ & $182(62.12)$ & 02.17 & 0.33 \\
\hline & Female & $52(46.85)$ & $31(27.93)$ & $28(25.22)$ & $111(37.88)$ & & \\
\hline \multirow[t]{5}{*}{ Semester } & First & $52(43.70)$ & $38(31.93)$ & $29(24.37)$ & $119(40.61)$ & 16.70 & 0.03 \\
\hline & Third & $23(29.11)$ & $31(39.24)$ & $25(31.65)$ & $79(26.96)$ & & \\
\hline & Fifth & $15(31.25)$ & $21(43.75)$ & $12(25.00)$ & $48(16.38)$ & & \\
\hline & Seventh & $09(37.50)$ & $11(45.83)$ & $04(16.67)$ & $24(08.19)$ & & \\
\hline & Ninth & $16(69.56)$ & $04(17.39)$ & 03(13.05) & $23(07.85)$ & & \\
\hline \multirow[t]{2}{*}{ Residence } & Day scholar & $58(51.79)$ & $36(32.14)$ & $18(16.07)$ & $112(38.2)$ & 13.60 & $<0.001$ \\
\hline & Hostel resident & $57(31.49)$ & $69(38.12)$ & $55(30.39)$ & $181(61.8)$ & & \\
\hline \multirow[t]{2}{*}{ Type of family } & Joint & $21(38.18)$ & $18(32.73)$ & $16(29.09)$ & $55(18.77)$ & 00.67 & 0.71 \\
\hline & Nuclear & $94(39.50)$ & $87(36.55)$ & $57(23.95)$ & $238(81.23)$ & & \\
\hline \multirow[t]{5}{*}{ PCMI(Rs/month) } & $<938$ & $01(50.00)$ & $01(50.00)$ & $00(00.00)$ & $02(00.68)$ & 2.64 & 0.95 \\
\hline & $939-1875$ & $06(46.16)$ & $04(30.77)$ & $03(23.07)$ & $13(04.44)$ & & \\
\hline & $1876-3126$ & $06(54.55)$ & $03(27.274$ & 02(18.18) & $11(03.75)$ & & \\
\hline & $3127-6253$ & $14(37.84)$ & $12(32.43)$ & $11(29.73)$ & $37(12.63)$ & & \\
\hline & $>6254$ & $88(38.26)$ & 85 (36.96) & $57(24.78)$ & $230(78.50)$ & & \\
\hline \multirow[t]{4}{*}{ BMI (in $\left.\mathrm{kg} / \mathrm{m}^{2}\right)$} & $<18.5$ & $12(38.71)$ & $10(32.26)$ & $09(29.03)$ & $31(10.58)$ & 08.67 & 0.19 \\
\hline & $18.5-24.9$ & $91(43.13)$ & $69(32.70)$ & $51(24.17)$ & $211(72.01)$ & & \\
\hline & $25-29.9$ & $11(22.92)$ & $25(52.08)$ & $12(25.00)$ & $48(16.38)$ & & \\
\hline & $30-34.9$ & $01(33.33)$ & $01(33.33)$ & $01(33.34)$ & 03(01.03) & & \\
\hline \multirow[t]{2}{*}{ Habit of exercise } & Yes & $74(46.25)$ & $58(36.25)$ & $28(17.50)$ & $160(54.61)$ & 12.20 & $<0.001$ \\
\hline & No & $41(30.83)$ & $47(35.34)$ & $45(33.83)$ & $133(45.39)$ & & \\
\hline \multirow[t]{2}{*}{ Tobacco intake } & Yes & $13(33.33)$ & $15(38.46)$ & $11(28.21)$ & $39(13.31)$ & 00.68 & 0.71 \\
\hline & No & $102(40.16)$ & $90(35.43)$ & $62(24.41)$ & $254(86.69)$ & & \\
\hline \multirow[t]{2}{*}{ Alcohol intake } & Yes & $12(32.43)$ & $14(37.84)$ & $11(29.73)$ & $37(12.63)$ & 00.94 & 0.62 \\
\hline & No & $103(40.23)$ & $91(35.55)$ & $62(24.22)$ & $256(87.37)$ & & \\
\hline \multirow[t]{2}{*}{ Excessive Caffeine intake } & Yes & $82(37.96)$ & $84(38.89)$ & $50(23.15)$ & $216(73.72)$ & 03.51 & 0.17 \\
\hline & No & $33(42.86)$ & $21(27.27)$ & $23(29.87)$ & $77(26.28)$ & & \\
\hline \multirow[t]{2}{*}{ Mobile, laptop, internet $>2 \mathrm{~h} / \mathrm{d}$} & Yes & $114(39.58)$ & $103(35.76)$ & $71(24.66)$ & $288(98.29)$ & 00.96 & 0.61 \\
\hline & No & $01(20.00)$ & $02(40.00)$ & $02(40.00)$ & $05(01.71)$ & & \\
\hline Total & & $115(39.25)$ & $105(35.84)$ & $73(24.91)$ & $293(100.00)$ & & \\
\hline
\end{tabular}

On the other hand, some older studies showed comparatively lower results. ${ }^{14-19}$ A study by Feng et al. at China revealed $19.17 \%$ of the medical students had poor sleep quality, ${ }^{14}$ corresponding figures were $16 \%$ among Malaysian medical students by Zailinawati et al..$^{15} 50.9 \%$ by Brick et al. at California University, ${ }^{16} 59.4 \%$ in Lithuanian study (Europe) by Preišegolavičiūtè et al. ${ }^{17} 52.0 \%$ of males and $58.4 \%$ of females experienced poor sleep quality in a study by Sanchez et al. at Peru ${ }^{18}$ and Vargas et al. at America described that $51 \%$ medical students were poor-quality sleepers. ${ }^{19}$

This discrepancy might be explained by differences in sample sizes, race and study population. Moreover, in recent years there is a marked increase in the night use of social media, which increase the number of poor sleepers as opposed to older years.
In this particular study the sleep quality was almost similar in both gender, similar to Delhi ${ }^{12}$ and China. ${ }^{14}$ However, here our findings are not consistent with those of some other studies: in Maharashtra study by Giri et al. females had better sleep quality than males. ${ }^{20}$ This might be due to substance abuse in males. In contrast females were more poor sleepers compared to males, which agrees with many previous studies. ${ }^{10,12,21-23}$ This may be attributed to more prevalence of psychological problems like anxiety and depression among females compared to males,

This study and some other studies demonstrated that age group $<=20$ years had poorer sleep than higher age group..$^{14,16,23}$

This may be attributed to the fact that younger students are in the preclinical and para-clinical years, they might not adapted to high load after 
studying at higher secondary schools. Moreover, anxiety for passing the first professional MBBS might also play some role.

Sleep scores showed a correlation with semesters, wherein sleep quality improves as students advance in academic years in this study and other studies. ${ }^{10}$ This may be due to the fact that over time, as students become mature and accustomed to their academic schedules, they also learn how to improve their sleep habits.

Students live in hostel campus in the present study had more prevalence of poor sleep quality compared to those living with their family. This result was in line with Saudi Arabia ${ }^{10}$ and Egyptian study. ${ }^{23}$

Medical students experience high level of stress due to academic reasons which affects adversely their sleep and this inadequate sleep cause daytime sleepiness, ultimately leading to smoking, alcohol abuse, depression, anxiety and poor interpersonal communication. In the present study, about $41 \%$ reported stress, similar to study by Giri et al. ${ }^{20}$ Gassara et al. ${ }^{11}$ Feng et al. ${ }^{14}$ and Preišegolavičiūtè et al. ${ }^{17}$ In Saudi Arabia ${ }^{10}$ and Maharashtra study ${ }^{20}$ anxiety was the first predictor of poor sleep quality. Egyptian study ${ }^{19}$ described presence of a significant positive correlation between anxiety and PQSI scores.

The effect of lifestyle including BMI and exercise in physical and mental well-being have been demonstrated in many studies. Ibrahim et al. demonstrated presence of negative associations between BMI and sleep quality. ${ }^{10} \mathrm{BMI}$ revealed a significant association with sleep estimated by both Global PQSI and EDSS score in Maharashtra ${ }^{20}$ and our study. Moreover, those who exercise daily showed less sleep disturbance. ${ }^{20}$

This study documented that smokers had poor sleep compared to nonsmokers similar to the results from Maharashtra ${ }^{20}$ and Saudi Arabia. ${ }^{10}$ Study by Gassara, et al. ${ }^{11}$ revealed significant association with alcohol consumption like our study.

This study and many other previous studies ${ }^{20}$ described an association of sleep with excessive caffeine intake, smoking, alcohol and long-time use of mobile phone/laptop. The present study result revealed that excessive consumption of caffeine was associated with poor sleep which agrees with the findings of Ibrahim et al. ${ }^{10}$ and Sanchez et al. ${ }^{18}$ However Saudi Arabia study ${ }^{10}$ results revealed absence of statistical association between the night use of social media and sleep quality.

In this study, day time sleepiness was present in $24.91 \%$ of the study population, which was higher than a study by Giri et al. at Maharashtra $(17.3 \%),{ }^{20}$ and lower than study by Priya et al. at Pawapuri (37.13\%), ${ }^{9}$ Ibrahim et al. at Saudi Arabia (37.3\%), ${ }^{10}$ Machado-Duque et al. at Universidad Tecnológica de Pereira (Columbia) $(49.8 \%)^{13}$ and Zailinawati et al. at Malayasia (35.5\%). ${ }^{15}$ EDS was significantly higher in the study population with poor sleep quality in the present study. This result agrees with the results of a many other studies. ${ }^{9,10,13,21,22}$

In the present study, daytime sleepiness was significantly associated with lower age group, year of study, hostel residence and exercise.

\section{Strengths and limitations}

\section{Strengths include}

1. Validated tools for measuring sleep quality.

2. Anthropometric measures were done by trained research personnel using calibrated instruments.

3. Dearth of data about sleep quality of undergraduate medical students in India including West Bengal and Kolkata.

However, the results of our study should be interpreted in context of some limitations.

First, instead of using random sampling technique, we considered convenience sampling method.
Second, as this study followed a cross-sectional data collection design, the temporal relationship between poor sleep quality and socio demographic and lifestyle factors cannot be determined. A longitudinal study design would be better.

Third, this study was conducted from one medical college, therefore the result cannot be generalised to all medical students. A multi-centre study would be better to improve generalizability.

Fourth, association of sleep quality with one very important determinant, i,e; academic performance was not assessed.

Lastly, the major limitation of the study is that it is based only on subjective assessment by the study population. Incorrect information may be provided by them and they may also be unable to understand or may misinterpret the questions.

\section{CONCLUSION}

The present study revealed very high prevalence of poor sleep quality (63.48\%) among undergraduate medical students as per PSQI scale. Day time sleepiness was present in $24.91 \%$ of the study population as per EDSS scale. Sleep quality was associated with lower age group, hostel residence, lower years of study, BMI, lack of exercise, stress, smoking, alcohol consumption, excessive caffeine intake, use of social media for prolong period.

To improve the sleep quality of medical students, we should provide a positive environment and greater support. This can be done by establishing counselling facilities and promoting good sleep hygiene that can serve a positive change towards their quality of life and coping with their stressful environment.

Medical students also have to identify their impediments and seek for an advice from the faculty in order to find solutions for it.

\section{ACKNOWLEDGEMENT}

We thank the Director, Dean and MSVP of IPGME\&R, Kolkata for permitting us to conduct the study and lending us all kinds of support during the study. We also thank the medical students for their kind cooperation and patience during the study.

\section{Scope for further studies}

A prospective study that follows students through their medical college years may help to better understand the phenomenon.

\section{CONFLICT OF INTEREST}

There are no potential, perceived, or real competing and/or conflicts of interest among authors regarding the article.

\section{ABBREVIATIONS}

ASP: Average Sleep Propensity; BMI: Body Mass Index; CDC: Center for Disease Control; CI: Confidence Interval; EDS: Excessive Daytime Sleepiness; EDSS: Epwoth Daytime Sleepiness Scale; WHO: World Health Organization; PCMI: Per Capita Monthly Income; PSQI: Pittsburgh Sleep Quality Index; SPSS: Statistical Package for Social Sciences.

\section{REFERENCES}

1. Azad MC, Fraser K, Rumana N, Abdullah AF, Shahana N, Hanly PJ, et al. Sleep disturbances among medical students: A global perspective. J Clin Sleep Med. 2015;11(1):69-74.

2. Aldabal L, Bahammam AS. Metabolic, endocrine and immune consequences of sleep deprivation. Open Respir Med J. 2011;5:31-43.

3. Brown FC, Buboltz WC, Soper B. Development and evaluation of the Sleep Treatment and Education Program for Students (STEPS). J Am Coll Health. 2006;54(4):231-7.

4. Waqas A, Khan S, SharifW, Khalid U, Ali A. Association of academic stress with 
sleeping difficulties in medical students of a Pakistani medical school: A cross sectional survey. Peer J. 2015;3:e840.

5. Ibrahim N, Al-Kharboush D, El-Khatib L, Al-Habib A, Asali D. Prevalence and predictors of anxiety and depression among female medical students in King Abdulaziz University, Jeddah, Saudi Arabia. Iran J Public Health. 2013;42(7):726-36.

6. Buysse DJ, Reynolds CF, MonkTH, Berman SR, Kupfer DJ. The Pittsburgh Sleep Quality Index (PSQI): A new instrument for psychiatric research and Practice. Psychiatry Res. 1989;28(2):193-213.

7. Barron JO, Lu K, Jacobsen K, Israel H, Cannada LK. Sleep Disturbances in Orthopaedic Trauma Patients. JACS. 2017;225(4):145

8. Johns MW. A New Method for Measuring Daytime Sleepiness: The Epworth Sleepiness Scale. Sleep. 1991;14(6):540-5. Available from epworthsleepinessscale.com/about-the-ess/

9. Priya J, Kumari S, Singh J. The relationship between sleep quality and daytime sleepiness on the academic performance of medical students. Indian Journal of Basic and Applied Medical Research. 2017;6(3):59-6.

10. Ibrahim NK, Badawi FA, Mansouri YM, Ainousa AM, Jambi SK, Fatani AN, et al. Sleep Quality among Medical Students at King Abdulaziz University: A Crosssectional Study. J Community Med Health Educ. 2017;7(5):561-6.

11. Gassara I, Ennaoui R, Halwani N, Turki M, Aloulou J, Amami O. Sleep quality among medical students. European Psychiatry. 2016;33:5594.

12. Shad R, Thawani R, Goel A. Burnout and Sleep Quality: A Cross-Sectional Questionnaire-Based Study of Medical and Non-Medical Students in India. Cureus. 2015;7(10):361-71.

13. Machado-Duque ME, Echeverri CJE, Machado-Alba JE. Excessive daytime sleepiness, poor quality sleep and low academic performance in medical stu- dents. Rev Colomb Psiquiatr. 2015;44(3):137-42.

14. Feng G, Chen J, Yang X. Study on the status and quality of sleep-related influencing factors in medical college students. Zhonghua Liu Xing Bing Xue Za Zhi. 2005;26(5):328-31.

15. Zailinawati $A H$, Teng $C L$, Chung $Y C$, Teow TL, Lee PN, Jagmohni KS. Daytime sleepiness and sleep quality among Malaysian medical students. Med J Malaysia. 2009;64(2):108-10.

16. Brick CA, Seely DL, Palermo TM. Association between sleep hygiene and sleep quality in medical students. Behav Sleep Med. 2010;8(2):113-21.

17. Preišegolavičiūtè $E$, Leskauskas $D$, Adomaitienè $V$. Associations of quality of sleep with lifestyle factors and profile of studies among Lithuanian students. Medicina. 2010;46(7):482-9.

18. Sanchez SE, Martinez C, Oriol RA, Yanez D, Castañeda B, Sanchez E, et al. Sleep quality, sleep patterns and consumption of energy drinks and other caffeinated beverages among Peruvian college students. Health. 2013;5(8B):26-35.

19. Vargas PA, Flores M, Robles E. Sleep quality and body mass index in college students: The role of sleep disturbances. J Am Coll Health. 2014;62(8):534-41.

20. Giri PA, Baviskar MP, Phalke DB. Study of Sleep Habits and Sleep Problems among Medical Students of Pravara Institute of Medical Sciences Loni, Western Maharashtra, India. Ann Med Health Sci Res. 2013;3(1):51-4.

21. Yogesh S, Abha S, Priyanka S. Mobile usage and sleep patterns among medical students. Indian J Physiol Pharmacol. 2014;58(1):100-3.

22. Surani AA, Zahid S, Surani A, Ali S, Mubeen M, Khan RH. Sleep quality among medical students of Karachi, Pakistan. J Pak Med Assoc. 2015;65(4):380-2.

23. Fawzy M, Hamed SA. Prevalence of psychological stress, depression and anxiety among medical students in Egypt. Psychiatry Res. 2017;255:186-94.

Cite this article : Basu M, Saha SK, Majumder S, Chatterjee S, Misra R. A Study on Sleeping Pattern among Undergraduate Medical Students of a Tertiary Care Teaching Hospital of Kolkata. Int J Med Public Health. 2019;9(4):118-24. 